\title{
Os benefícios da aprendizagem baseada em problemas para os universitários da área da saúde: uma revisão bibliográfica
}

\author{
The benefits of problem-based learning for health students: a bibliographic review \\ Los beneficios del aprendizaje basado en problemas para estudiantes de salud: una \\ revisión bibliográfica
}

Camila de Souza Lopes ${ }^{1 *}$, Marcos Antonio Nunes Araujo¹.

\section{RESUMO}

Objetivo: Descrever a metodologia de Aprendizagem Baseada em Problemas para os universitários da área da saúde e apontar seus benefícios para o processo de ensino-aprendizagem. Métodos: Estudo de revisão bibliográfica, realizado nas bases de dados Scielo e Biblioteca Virtual em Saúde entre os anos de 2014 a 2019, no qual totalizaram 10 estudos. Os descritores utilizados foram: "Educação", "Aprendizagem Baseada em Problemas" e "Metodologias". Os trabalhos selecionados foram os que exploravam o potencial da aprendizagem baseada em problemas para a construção do conhecimento e desenvolvimento de habilidades e atitudes condizentes com uma aprendizagem significativa. Resultados: As estratégias de ensinoaprendizagem interativas e dinâmicas fazem com que os estudantes de saúde tenham um melhor desenvolvimento em seus conhecimentos não apenas teóricos, mas também nas habilidades da aplicabilidade prática. Considerações finais: A articulação entre diretrizes curriculares e realidade profissional deve ser alinhada, para que haja reorientação de saberes e de práticas tanto no espaço acadêmico como fora dele. O professor é o facilitador da produção do aprendizado e o aluno o protagonista para obter o conhecimento. As discussões críticas e reflexivas fazem com que os participantes se sintam desafiados diante da resolutividade de problemas, o que se difere dos métodos tradicionais de ensino, tornando a aula interessante.

Palavras-chave: Educação, Aprendizagem baseada em problemas, Metodologias.

\begin{abstract}
Objective: To describe the problem-based learning methodology for health university students and to point out its benefits for the teaching-learning process. Methods: This is an integrative review of studies available in the Scielo and Virtual Health Library databases, published between the years 2014 and 2019, in which there were 10 studies. The descriptors used were: "Education", "Problem Based Learning" and "Methodologies". The selected studies were those that explored the potential of problem-based learning for knowledge development of attitudes consistent with meaningful learning. Results: Interactive and dynamic teachinglearning strategies enable health students to better develop not only theoretical knowledge but also practical applicability skills. Final considerations: The articulation between curriculum guidelines and professional reality must be aligned, so that there is a reorientation of knowledge and practices both within and outside the academic space. The teacher is the facilitator of the learning production and the student the protagonist to obtain the knowledge. Critical and reflective discussions make participants feel challenged in the face of problem solving, which differs from traditional teaching methods making the class stimulating.
\end{abstract}

Keywords: Education, Problem based learning, Methodologies.

1Universidade Estadual do Mato Grosso do Sul. Dourados - MS. *E-mail: camiladesouzalopes@gmail.com 


\section{RESUMEN}

Objetivo: Describir la metodología de aprendizaje basada en problemas para estudiantes universitarios de salud y señalar sus beneficios para el proceso de enseñanza-aprendizaje. Métodos: Un estudio de revisión de literatura realizado en las bases de datos Scielo y Biblioteca Virtual en Salud, publicados entre 2014 a 2019 y que ascendió a doce estudios. Los descriptores utilizados fueron: "Educación", "Aprendizaje Basado en Problemas" y " Metodologías". Los trabajos seleccionados fueron aquellos que exploraron el potencial del aprendizaje basado en problemas para el desarrollo del conocimiento y el desarrollo de habilidades y actitudes consistentes con el aprendizaje significativo. Resultados: Las estrategias interactivas y dinámicas de enseñanza-aprendizaje hacen que los estudiantes de salud desarrollen mejor no solo el conocimiento teórico sino también las habilidades prácticas de aplicabilidad. Consideraciones finales: La articulación entre las pautas curriculares y la realidad profesional debe estar alineada, de modo que haya una reorientación del conocimiento y las prácticas tanto dentro como fuera del espacio académico. El profesor es el facilitador de la producción de aprendizaje y el alumno el protagonista para obtener el conocimiento. Las discusiones críticas y reflexivas hacen que los participantes se sientan desafiados ante la resolución de problemas, que difiere de los métodos de enseñanza tradicionales que hacen que la clase sea estimulante.

Palabras clave: Educación, Aprendizaje basado en problemas, Metodologías.

\section{INTRODUÇÃO}

A Abordagem Tradicional vem sido amplamente discutida entre estudiosos e profissionais da área por possuir características em seu processo contra as tendências educacionais atuais. Abordagens tradicionais estão formando alunos que não possuem habilidade em intervir sobre os problemas da prática profissional e que não possuem a capacidade de implementar ações transformadoras nos cenários da prática. Sem a visão crítica e reflexiva, tornam-se futuros profissionais passivos (MORGADO S, et al., 2016).

Existem muitas desvantagens nos métodos tradicionais de ensino, tanto pela dificuldade do docente exemplificar a prática apenas por meio de aulas expositivas, quanto para o aluno no que se refere ao entendimento da aplicabilidade prática da teoria exposta. Nesse contexto educacional o processo de educação que deveria envolver professor-aluno e ensino-aprendizagem e/ou vice-versa, é falho, pois o professor é visto como um ditador em sala de aula, e praticamente não há uma relação entre ele e os alunos (BORGES MC, et al., 2019). Devido a este processo, os cursos de graduação em saúde e de outras áreas têm sido estimulados a incluírem, em suas reorganizações, metodologias ativas de ensino que permitam dar conta dos novos perfis delineados para os futuros profissionais. As propostas de ensino aprendizagem provocam mudanças nos processos de formação e essas propostas não podem mais ser construídas de maneira isolada, sem levar em consideração as problematizações das necessidades locais. Ensinar é um processo complexo, a metodologia do ensinar e como se ensinar é construído pelas experiências proporcionadas pelos problemas criados através de uma ação desencadeadora (AGUIAR RG, et al., 2014).

Incorporar no ensino atual, formas de ensinar que possam desenvolver nas estudantes competências adequadas ao contexto social e profissional, permitindo a eles efetiva preparação para a realidade que se apresenta, faz com que a Aprendizagem Baseada em Problemas (ABP) ganhe destaque para expandir as possibilidades de construção do conhecimento e desenvolvimento de habilidades e atitudes condizentes com uma aprendizagem significativa. Estimular no estudante a capacidade de inovação, empreendedorismo, criticidade e visão holística, é um dos objetivos dessa prática (OLIVEIRA, et al., 2015).

A ABP surgiu no final da década de 60 na Faculdade de Medicina da Universidade McMaster, em Hamilton, no Canadá. John Evans assumiu em 1965, a reitoria da escola de medicina e tinha o desejo de executar mudanças no ensino aprendizagem da medicina. Ele selecionou quatro jovens médicos para formar o Comitê de Educação da McMaster, conhecidos como os Cinco Fundadores. Esta estratégia de estruturação de currículo foi criada para substituir os tradicionais conceitos e práticas de ensino tradicionais, na qual o aluno era formado apenas com ensinamentos teóricos. Foi o marco inicial para a prática médica dos acadêmicos.

REAS/EJCH | Vol.Sup.n.40 | e1695 | DOI: https://doi.org/10.25248/reas.e1695.2020 Página 2 de 8 
Posteriormente, houve uma grande difusão da ABP nos Estados Unidos, Europa e pelo mundo. O método não ficou sendo assimilado apenas para a área da saúde, mas também para várias áreas de conhecimento (HILLEN H, et al., 2010).

A primeira fase do processo da ABP acontece de forma que os alunos são apresentados a um problema para que seja verificado o seu conhecimento prévio ao discutir em grupo e propor as possíveis soluções para a temática. Posteriormente, os alunos formulam perguntas que orientam outras atividades de estudo da prédiscussão da emblemática. Na segunda fase, os alunos estudam literaturas relevantes para a resolução das questões apresentadas. A terceira fase é chamada de resolução do problema, em que se encontram os pontos chave para as questões problematizadoras. A síntese e avaliação do processo que constitui a quarta fase, é realizada entre professor e alunos, em que há a verificação se todos os problemas incialmente formulados foram resolvidos. (HMELO-SILVER C, 2014).

Esta metodologia ativa é centrada no aluno, que abandona o papel de receptor passivo de conhecimento, e torna-se o protagonista de seu próprio aprendizado por meio de pesquisa. O professor torna-se apenas um facilitador da aprendizagem. O estímulo da atividade do aluno, o incentivo para a sua autonomia e desenvolvimento cognitivo, a importância do trabalho em equipe e o aumento do senso de responsabilidade de obter a resolução dos problemas, faz com que a ABP seja uma metodologia inovadora, diferenciada das metodologias tradicionais (HMELO-SILVER C, 2014).

Em virtudes dos fatos mencionados, o objetivo desta presente pesquisa foi realizar uma revisão bibliográfica e se propõe a descrever a metodologia de ABP e apontar seus benefícios para os universitários da área da saúde. As metodologias ativas constituem o único aporte relacionado ao processo de ensinoaprendizagem nesta pesquisa, porém não são aplicáveis a todos os contextos.

\section{MÉTODOS}

Este artigo de revisão bibliográfica aborda a ABP como ferramenta de apoio ao ensino-aprendizagem. Pretende-se descrever e analisar seus benefícios reconhecendo-a como uma metodologia motivadora de ensino para os estudantes de graduação do Brasil. Esta pesquisa foi realizada nas bases de dados Scielo e Biblioteca Virtual em Saúde entre os anos de 2014 a 2019. Os critérios de inclusão adotados foram os trabalhos que exploravam o potencial da ABP para a construção do conhecimento e desenvolvimento de habilidades condizentes com uma aprendizagem significativa. Foram excluídos trabalhos que não apresentassem seu texto na íntegra e que não contivessem ano de publicação, volume e número em revista. 


\section{Revista Eletrônica Acervo Saúde / Electronic Journal Collection Health ～ISSN 2178-2091}

Tabela 1 - Publicações relacionadas aos benefícios da Aprendizagem Baseada em Problemas.

\begin{tabular}{|c|c|c|c|c|c|}
\hline Trabalho & Ano & Autor & Revista & Objetivos & Resultados \\
\hline T1 & 2019 & $\begin{array}{c}\text { JUNIOR RRF, et } \\
\text { al. }\end{array}$ & $\begin{array}{l}\text { Revista Trabalho, } \\
\text { Educação e Saúde. }\end{array}$ & $\begin{array}{l}\text { Realizar mapeamento na Revista } \\
\text { Brasileira de Educação Médica } \\
\text { com base na produção científica } \\
\text { sobre conexões entre formação } \\
\text { médica e metodologias ativas. }\end{array}$ & $\begin{array}{l}\text { As metodologias ativas proporcionaram } \\
\text { respostas positivas para a mudança } \\
\text { curricular dos cursos de Medicina no Brasil, } \\
\text { porém apenas a mudança da metodologia } \\
\text { não é suficiente para a mudança do perfil } \\
\text { do egresso de medicina. }\end{array}$ \\
\hline T2 & 2019 & LIMA AD, et al. & $\begin{array}{l}\text { Revista Brasileira de } \\
\text { Educação Médica. }\end{array}$ & $\begin{array}{l}\text { Relatar a experiência docente no } \\
\text { ensino de graduação na área de } \\
\text { Medicina, com diferentes } \\
\text { estratégias de ensino e de } \\
\text { avaliação, incluindo metodologias } \\
\text { ativas e práticas interdisciplinares. }\end{array}$ & $\begin{array}{l}\text { A Metodologia Baseada em Problemas } \\
\text { permitiu aos estudantes de Medicina } \\
\text { adquirir o desenvolvimento de habilidades e } \\
\text { competências do teórico com a prática. A } \\
\text { integração do conhecimento estimulado } \\
\text { com o interesse fez com que a participação } \\
\text { do discente fosse mais constante. }\end{array}$ \\
\hline T3 & 2018 & $\begin{array}{c}\text { CONCEIÇÃO CV, } \\
\text { et al. }\end{array}$ & $\begin{array}{l}\text { Revista Brasileira de } \\
\text { Educação Médica. }\end{array}$ & $\begin{array}{l}\text { Explorar a percepção de } \\
\text { estudantes e docentes sobre } \\
\text { aprendizagem cooperativa em um } \\
\text { currículo médico baseado na ABP. }\end{array}$ & $\begin{array}{l}\text { As habilidades de comunicação, raciocínio } \\
\text { crítico, interdependência positiva, avanços } \\
\text { em trabalho em equipe, além de boa } \\
\text { aquisição de conhecimento cognitivo foram } \\
\text { garantidos neste processo de ensino } \\
\text { aprendizagem do curso de Medicina. }\end{array}$ \\
\hline T4 & 2018 & $\begin{array}{c}\text { SAMPAIO CL, et } \\
\text { al. }\end{array}$ & $\begin{array}{l}\text { Revista de } \\
\text { Enfermagem. }\end{array}$ & $\begin{array}{l}\text { Relatar uma experiência } \\
\text { metodológica de aprendizagem, } \\
\text { baseada em problemas, na } \\
\text { disciplina de Tanatologia. }\end{array}$ & $\begin{array}{c}\text { Considerou-se uma estratégia viável, de } \\
\text { baixo custo e os alunos se avaliaram como } \\
\text { agentes reflexivos construtores do próprio } \\
\text { crescimento pessoal e profissional sobre } \\
\text { Tanatologia. }\end{array}$ \\
\hline
\end{tabular}

REAS/EJCH | Vol.Sup.n.40 | e1695 | DOI: https://doi.org/10.25248/reas.e1695.2020 Página 4 de 8 


\section{Revista Eletrônica Acervo Saúde / Electronic Journal Collection Health ～ISSN 2178-2091}

\begin{tabular}{|c|c|c|c|c|c|}
\hline T5 & 2018 & $\begin{array}{c}\text { MARQUES } \\
\text { LMNSR, et al. }\end{array}$ & $\begin{array}{c}\text { Revista Escola Anna } \\
\text { Nery. }\end{array}$ & $\begin{array}{l}\text { Refletir sobre como as } \\
\text { metodologias ativas de ensino- } \\
\text { aprendizado são importantes } \\
\text { estratégias para os professores } \\
\text { trabalharem a educação em } \\
\text { valores na graduação em } \\
\text { enfermagem. }\end{array}$ & $\begin{array}{l}\text { As metodologias ativas promoveram } \\
\text { características desejadas para os futuros } \\
\text { enfermeiros, tornou-se indispensável } \\
\text { transformar as fundamentações teóricas } \\
\text { sobre educação em valores e práticas } \\
\text { pedagógicas. }\end{array}$ \\
\hline T6 & 2018 & $\mathrm{CHINI} \mathrm{H}$, et al. & $\begin{array}{l}\text { Revista Brasileira de } \\
\text { Educação Médica. }\end{array}$ & $\begin{array}{l}\text { Identificar as atividades de } \\
\text { integração curricular baseadas na } \\
\text { problematização de casos da } \\
\text { atenção primária à saúde nas } \\
\text { escolas médicas brasileiras. }\end{array}$ & $\begin{array}{l}\text { A estratégia de aprendizagem por } \\
\text { problemas contribuiu para o } \\
\text { desenvolvimento do raciocínio clínico } \\
\text { contextualizado dos médicos, visando à } \\
\text { formação de um profissional competente, } \\
\text { que atue com responsabilidade social. }\end{array}$ \\
\hline T7 & 2016 & PINTO ML, et al. & Revista Abeno. & $\begin{array}{l}\text { Relatar a experiência da aplicação } \\
\text { da ABP com discentes do primeiro } \\
\text { ano do curso de Odontologia } \\
\text { como atividade de extensão. }\end{array}$ & $\begin{array}{l}\text { A ABP foi efetiva, principalmente no } \\
\text { desenvolvimento de habilidades e raciocínio } \\
\text { crítico para os alunos de Odontologia. O } \\
\text { conhecimento aprofundado em determinado } \\
\text { assunto teria sua importância diminuída } \\
\text { caso não fosse aplicado em situações reais. }\end{array}$ \\
\hline T8 & 2015 & SOUZA SC, et al. & Revista Holos. & $\begin{array}{l}\text { Apresentar a metodologia ABP } \\
\text { que tem se mostrado um } \\
\text { instrumento importante na } \\
\text { formação do profissional da saúde } \\
\text { e de outras áreas com vantagens } \\
\text { sobre o método de ensino } \\
\text { tradicional. }\end{array}$ & $\begin{array}{c}\text { A autoaprendizagem em ABP constitui uma } \\
\text { abordagem de ensino alternativa e, ao } \\
\text { mesmo tempo, inovadora. A } \\
\text { autossuficiência no uso de bibliotecas e } \\
\text { informações deveria ser oferecida a todos } \\
\text { os usuários, independentemente da } \\
\text { metodologia de ensino ou do nível de } \\
\text { graduação. }\end{array}$ \\
\hline
\end{tabular}

REAS/EJCH | Vol.Sup.n.40 | e1695 | DOI: https://doi.org/10.25248/reas.e1695.2020 Página 5 de 8 


\section{Revista Eletrônica Acervo Saúde / Electronic Journal Collection Health ～ISSN 2178-2091}

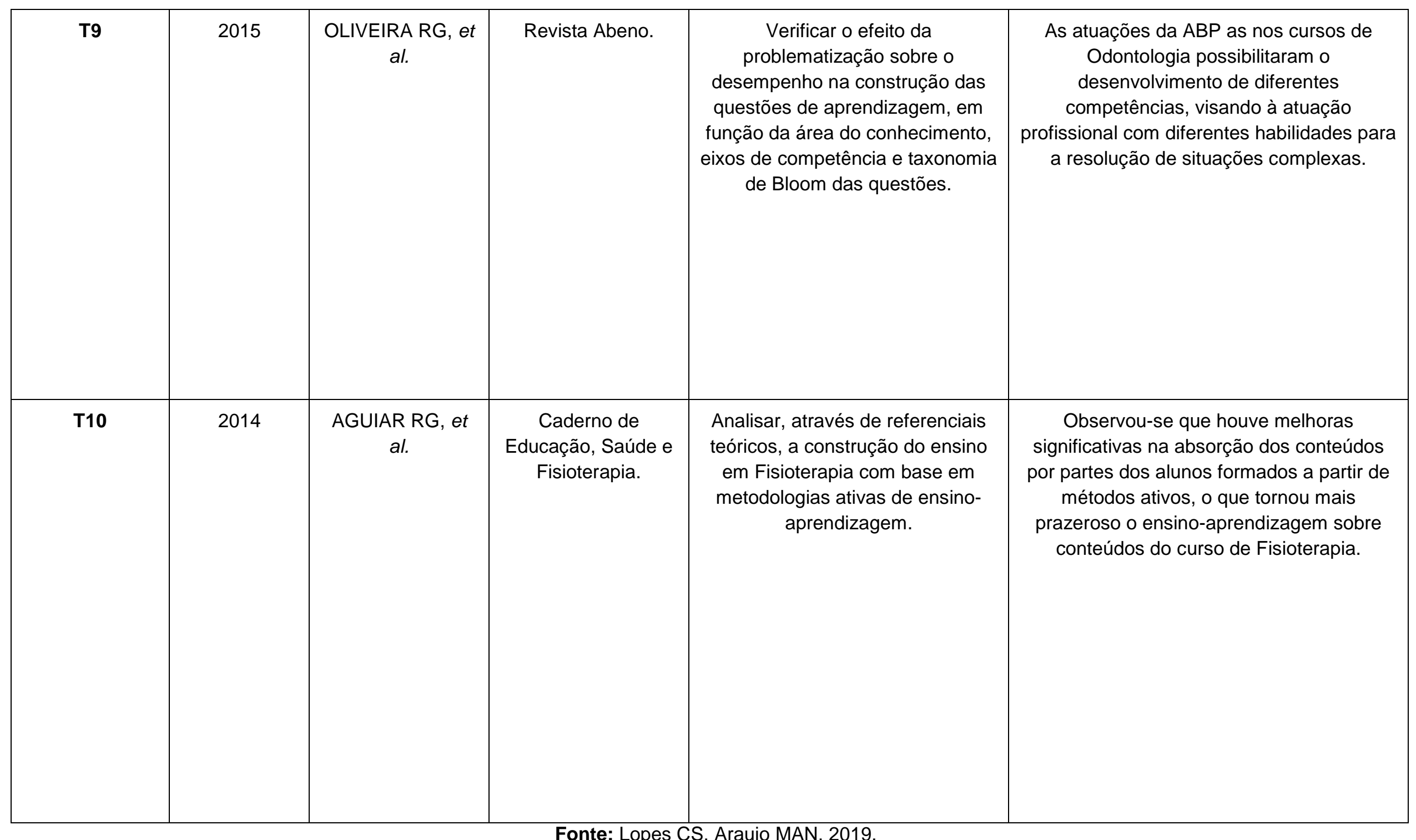




\section{RESULTADOS E DISCUSSÃO}

$\mathrm{Na}$ Tabela 1, apresenta a distribuição das publicações quanto ao ano, autor, revista publicada, objetivos e principais resultados relacionados aos benefícios da ABP para os universitários da área da saúde. As publicações estão dispostas em ordem alfabética, a partir da publicação mais atual.

A educação médica encontra-se em debate crítico em todos os contextos. As metodologias ativas são propostas que podem dar respostas aos anseios de mudança curricular dos cursos de medicina, superando o modelo tradicional de ensino, para que não haja a fragmentação do conhecimento científico (JUNIOR RRF E MAKNAMARA $M$ et al, 2019).

O emprego de metodologias ativas e a análise e escuta das críticas e sugestões construtivas dos alunos, estimula o interesse e participação dos discentes. Acredita-se que a ABP é uma transformação pedagógica dinâmica e inovadora, que direciona na tomada de decisões, e que atende ao enfrentamento dos desafios educacionais contemporâneos (LIMA AD, et al, 2019).

Os alunos apresentaram concepções quanto aos benefícios da aprendizagem cooperativa em pequenos grupos, julgando que habilidades de comunicação, raciocínio crítico, interdependência positiva, avanços em trabalho em equipe, além de boa aquisição de conhecimento cognitivo foram garantidos neste processo. À medida que avançavam nas séries, os estudantes apresentavam percepções diferentes em relação a diversas questões, este fato seja por conta da experiência com metodologias ativas de ensino aprendizagem (CONCEIÇÃO CV E MORAES MAA., 2018).

Com o uso da ABP no ensino da Tanatologia foi possível estimular a reflexão sobre a atuação do enfermeiro de forma mais humanizada e segura quanto às emoções de lidar com o sofrimento do outro, visto que é um desafio à aceitação da temática com naturalidade (SAMPAIO CL, et al., 2018).

As metodologias ativas contribuem para potencializar a sensibilidade moral, situações que permitam a vivência de conflitos morais. Torna-se importante a transformação das fundamentações teóricas com práticas pedagógicas. Ser professor exige compromisso ético, o mesmo deve star ciente de sua responsabilidade em ser agente transformador de opiniões (MARQUES LMNSR, 2018).

A integração de conteúdos básicos e clínicos problematizando casos vivenciados na comunidade está presente nos currículos médicos no Brasil em mais da metade das entrevistas realizadas. Sendo uma estratégia que contribui para o desenvolvimento do raciocínio clínico contextualizado, visando à formação de um profissional competente, que atue com responsabilidade social ( $\mathrm{CHINI} \mathrm{H}$, et al, 2018).

Os casos clínicos reais e hipotéticos apresentados com o objetivo de resgatar o conteúdo da estrutura curricular contribuíram para a formação do estudante de odontologia mais capacitado e mais seguro para a atuação no mercado de trabalho. A estratégia de se obter uma aprendizagem baseada em problemas e significativa torna o estudante mais capacitado para a realidade dos problemas que vierem acontecer em suas atividades rotineiras e profissionais. (PINTO ML, et al, 2016).

A metodologia facilitou o estudo e a compreensão da importância das metodologias ativas dos docentes em suas práticas profissionais. Há perspectivas de cada vez mais incluir essas metodologias de ensino aprendizagem na prática dos docentes para atender às Diretrizes Curriculares Nacionais do cenário atual (SOUZA SC E DOURADO L., 2015).

A problematização como método de ensino-aprendizagem foi observada por dois anos na Faculdade de Odontologia da Suprema. Baseado no relato dos estudantes, a metodologia incentivou a busca de informações e estimulou o aprender a aprender para a redução de inseguranças nos ambientes de trabalho (OLIVEIRA RG, et al., 2015).

A integração entre os espaços de aprendizagem e o aspecto do discente estar no centro do processo ensino-aprendizagem permite a construção de competências e habilidades condizentes com o novo perfil profissional exposto nas Diretrizes Curriculares Nacionais do curso de graduação de Fisioterapia. A organização curricular tem incentivado a integração ensino-serviço de maneira crítica e reflexiva (AGUIAR RG, et al., 2014). 


\section{CONSIDERAÇÕES FINAIS}

A articulação entre diretrizes curriculares e realidade profissional deve ser alinhada, para que haja reorientação de saberes e de práticas tanto no espaço acadêmico como fora dele. Na Aprendizagem Baseada em Problematização, o professor é o facilitador da produção do aprendizado e o aluno o protagonista para obter o conhecimento. As diretrizes curriculares nacionais estão sendo cada vez mais discutidas para que não haja a fragmentação do conhecimento científico teórico e prático pelos alunos de nível superior na área da saúde. A proposta de desvincular-se de um currículo apenas conteudista faz com que os participantes se sintam desafiados diante da resolutividade de problemas, o que se difere dos métodos tradicionais de ensino, tornando a aula estimulante e alunos não passivos. Não se pretende colocar a Aprendizagem Baseada em Problemas como a solução dos diversos problemas enfrentados pelo atual modelo educacional brasileiro e como a única alternativa para a transformação do perfil do aluno, mas como uma metodologia didática capaz de ajudar na busca de soluções para esses problemas vivenciados.

\section{REFERÊNCIAS}

1. AGUIAR RG, et al. Implantação de um Curso de Fisioterapia Baseado em Metodologias Ativas de Ensino Aprendizagem. Caderno de Educação e Saúde, 2014; 1(1): 13-18.

2. BORGES MC, et al. Aprendizagem Baseada em Problemas. Revista Medicina (Ribeirão Preto), 2019; 47(3): 301-307.

3. BARRETO NAP, et al. Percepção de Tutores quanto a sua Avaliação pelos Discentes de um Curso Médico. Revista Brasileira de Educação Médica, 2017; 41(2): 221-230.

4. CONCEIÇÃO CV, MORAES MAA. Aprendizagem Cooperativa e a Formação do Médico Inserido em Metodologias Ativas: um Olhar de Estudantes e Docentes. Revista Brasileira de Educação Médica, 2018; 42(4): 115-122.

5. CHINI H, et al. A Aprendizagem Baseada em Casos da Atenção Primária à Saúde nas Escolas Médicas Brasileiras. Revista Brasileira de Educação Médica, 2018; 42(2): 45-53.

6. HMELO-SILVER CE. Problem-Based Learning: What and How Do Students Learn? Educational Psychology Review, 2014; 16(3):235-262.

7. HILLEN H, et al. Lessons from Problem-Based Learning. New York: Oxford University Press, 2010; 1: 5-12.

8. JUNIOR RRF, MAKNAMARA M. A Literatura sobre Metodologias Ativas em Educação Médica no Brasil: Notas para uma Reflexão Crítica. Revista Trabalho, Educação e Saúde, 2019; 17(1): e0018214.

9. LIMA AD, et al. Avaliação, Ensinagem e Metodologias Ativas: uma Experiência Vivenciada no Componente Curricular Mecanismos de Agressão e de Defesa, no curso de Medicina da Universidade do Estado da Bahia, Brasil. Revista Brasileira de Educação Médica, 2019; 43(2): 216-224.

10. MARQUES LMNSR. As Metodologias Ativas como Estratégias para Desenvolver a Educação em Valores na Graduação em Enfermagem. Revista Escola Anna Nery, 2018; 22(3): 20180023.

11. MORGADO S, et al. Ensino orientado para a aprendizagem baseada na resolução de problemas e ensino tradicional: um estudo centrado em "transformação de matéria e de energia". Revista Ensaio Pesquisa e Educação em Ciências, 2016; 18(2) 73-98.

12. MEZZARI A. O Uso da Aprendizagem Baseada em Problemas (ABP) como Reforço ao Ensino Presencial Utilizando o Ambiente de Aprendizagem Moodle. Revista Brasileira de Educação Médica, 2011; 35 (1): 114-121.

13. OLIVEIRA RG, et al. Problematização como Método Ativo de Ensino- Aprendizagem em um Curso de Odontologia. Revista Abeno, 2015; 15(2): 74-81.

14. PINTO ML, et al. Ensino baseado em problemas como prática pedagógica aplicada a alunos ingressantes no curso de Odontologia. Revista da ABENO, 2016; 16(3): 28-35.

15. PERUZZI SL, FOFONKA L. A Importância da aula prática para a construção significativa do Conhecimento: A Visão dos Professores das Ciências da Natureza. Revista Educação Ambiental em Ação, 2014; 47: Ano XII.

16. SAMPAIO CL, et al. Aprendizagem baseada em problemas no ensino da Tanatologia, no curso de graduação em Enfermagem. Revista de Enfermagem, 2018; 22(3): e20180068.

17. SOUZA SC, DOURADO L. Aprendizagem baseada em problemas (ABP): um método de aprendizagem inovador para o ensino educativo. Revista Holos, 2015; 31(5): 182-200. 